[CONTRIBUTION FROM THE JOHN HARRISON LABORATORY OF CHEMISTRY, No. 75.]

\title{
THE ELECTROLYTIC DETERMINATION OF MANGANESE AND ITS SEPARATION FROM IRON AND ZINC. ${ }^{1}$
}

BY GEORge P. Scholl.

Received July 6, t503.

THE deposition of manganese as peroxide for quantitative estimations by electrolysis has been the subject of a great deal of investigation, as reference to its voluminous literature will disclose. $^{1}$

It was believed that formic acid, because of its simple constitution, would prove an excellent electrolyte and that under the right conditions very satisfactory results would be obtained with it. It was, therefore, tried with the addition of sodium formate.

The electrolysis was conducted as follows: Ten cc. of a solution of manganese sulphate ( $=0.1100$ gram of metal) were mixed with $5 \mathrm{cc}$. of formic acid (sp. gr. I.06), Io cc. of a sodium formate solution, containing I gram of the salt, and diluted to $\mathrm{I} 30 \mathrm{cc}$. with water so that the liquid covered I00 sq. $\mathrm{cm}$. of the surface of the dish. The dish was made the anode and a flat spiral the cathode, arranged as nearly as possible equidistant from the sides and the bottom of the dish to obtain as uniform a distribution of the current as possible. The current equaled I.4 amperes, the pressure between the electrodes being $\mathbf{2} 2$ volts at the beginning but decreasing to 8.6 volts at the end. It acted for one and onehalf hours, when, no further precipitation taking place, the liquid was siphoned off and replaced by water without interrupting the current. The deposit showed a deep black, shining color. It adhered firmly to the dish and was not detached on washing. Smith's statement ${ }^{1}$ that it is useless to try to obtain a definite compound by drying the deposit and that ignition to the protosesquioxide is necessary to secure definite and concordant results was found to be true. The results of four determinations made in exactly the same manner were:

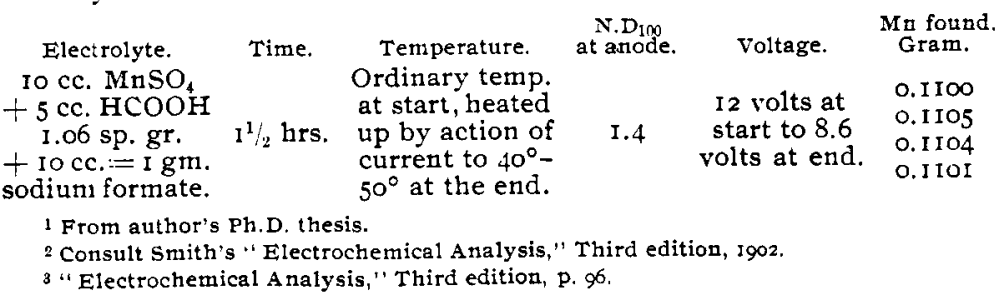


These demonstrated that it was quite possible to deposit the manganese completely in the presence of formic acid, even if the latter was present in amounts consiclerably above those given by Kaeppel as the maximum. ${ }^{1}$

According to Classen ${ }^{2}$ it is necessary to weigh the platinum dish after the deposit of peroxide has been removed from it, as the dish suffers a diminution of weight during electrolysis, amounting to about I mg. With the electrolyte used in the preceding experiments this did not take place, the dish losing either no weight at all or at the most only o.I mg.

The deposits were weighed without any difficulty. They slowly attracted moisture, however, and on standing over night gained perceptibly in weight.

Experiments were also conducted with low voltage to ascertain the effect of a lower current and consequently lower current density upon the deposit. The character of the latter remained unchanged. The application of heat $\left(50^{\circ}\right.$ to $\left.55^{\circ}\right)$ proved harmful. It was also ascertained that large quantities of sodium formate retarded the precipitation quite decidedly. Further, the weights of the deposits increased as the amount of sodium formate was increased. Indeed, it was scarcely possible to weigh those obtained where 2.5 grams of sodium formate had been present, even after ignition over a blast-lamp. The most reasonable explanation of this fact seemed to be that the sodium formate was partly decomposed by the current, with the formation of caustic soda at the cathode. This caustic soda, being specifically heavier than the electrolyte, fell to the bottom of the dish anode, and was enclosed and held mechanically by the precipitating manganese peroxide. It should be noted in this connection that careless washing of the deposit was entirely excluded.

The next step was, consequently, to do away with the source of error traceable to the addition of sodium formate and to try formic acid alone. The voltage required was high, on account of the low conductivity of the formic acid, it being 17.5 volts between the electrodes at the start, with a current strength of I ampere. As the solution became very warm in about an hour, the voltage was decreased to 7.9 rolts, giving an amperage of 0.8 . The deposit dicl not come down as quiclily as when sodium formate was pres-

1 Ztschr. anorg. Chem., 16, 268.

: "Ausgewählte Mrethoden," p. 369 . 
ent, but the manganese was all out after four hours. It was further found that the precipitate was absolutely non-hygroscopic after ignition, and could be weighed with perfect ease. It was left purposely exposed to the action of the atmosphere over night and reweighed on the following morning, when the weight was found to be the same. The appearance of the deposit was like that noticed before. As the determinations with employment of the spiral of platinum wire as cathode had necessitated such a high potential betweeen the electrodes in order to obtain the necessary strength of current and caused thereby objectionable heating of the electrolyte, it was decided to adopt some means to get along with as low a voltage as possible, and which would give the necessary current. Accordingly, a so-called basket electrode was used. This was a platinum dish, which conformed in shape to the interior surface of the roughened dish on which the precipitation of manganese peroxide took place. It had an area of $60 \mathrm{sq} . \mathrm{cm}$. and was perforated with holes to allow of a better egress of the gases set free during electrolysis and a better mixing of the solution. The following table gives the results of some experiments carried out with varying quantities of formic acid and varying quantities of manganese.

The deposits obtained were all very satisfactory and adherent. A slight disposition towards loosening was noticeable with those in which there was 0.2880 gram of manganese protosesquioxide present. It was, however, very slight, and, owing to the scaly nature of the material, it was quite easy to filter it out quickly on a small filter, wash, dry and remove it from the filter and add it to the bulk of the material in the dish, together with the ash of the filter-paper.

It is also apparent from the above table that the addition of more than $5 \mathrm{cc}$. of formic acid of 1.06 specific gravity has no beneficial effect. On the contrary, larger amounts of formic acid tend to retard the precipitation. Much less than $5 \mathrm{cc}$. of formic acid cannot be used, as there is a tendency to form flakes of a brown precipitate around the cathode, which have to be brought into solution again by the addition of more formic acid.

Other experiments were made to learn whether the addition of ammonium formate would have any accelerating or otherwise beneficial effect on the deposit. Such was not found to be the case. When chrome alum was introduced into the electrolyte, the 


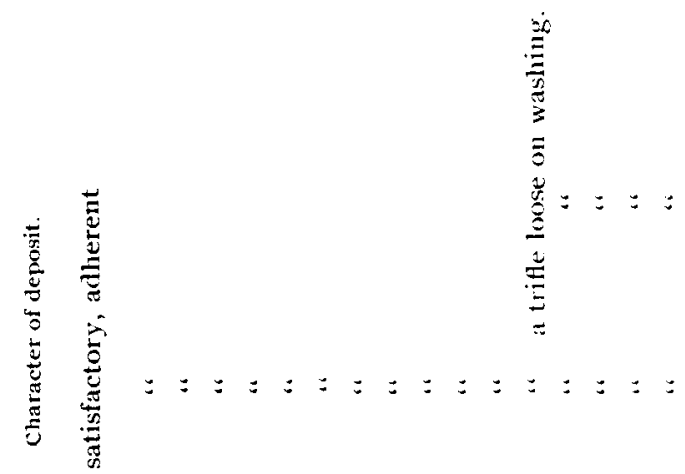

焉

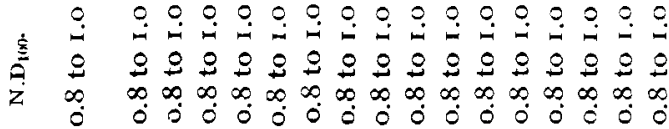

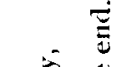

今心

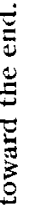

गु

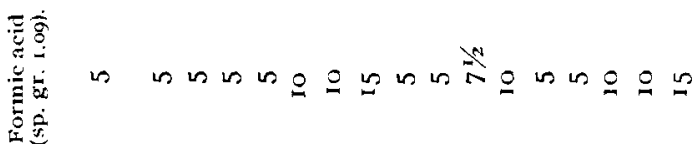

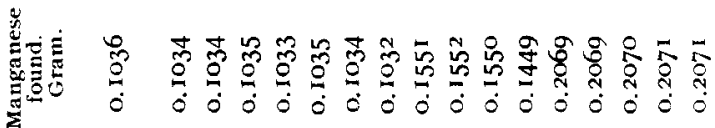

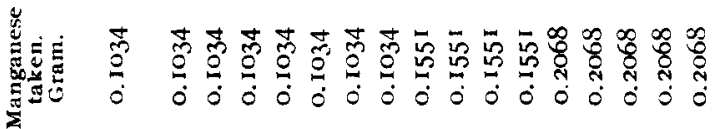


results were also very unsatisfactory. It may, therefore, be briefly concluded that:

( I) The statement of Kaeppel, that it is not possible to precipitate manganese completely in the presence of formic acid and that more than five drops of this acid prevent the deposition of manganese peroxide entirely, is not borne out by the experimental facts.

(2) It is possible to obtain the deposit of peroxide from a formic acid solution in a beautifully adherent and satisfactory form. which can be washed and ignited without any trouble.

(3) Formic acid is a better electrolyte than acetic acid, it being possible, according to Classen, ${ }^{1}$ to deposit not more than 0.08 gram of manganese in the form of peroxide when the latter is used.

The influence of other organic acids upon the precipitation of manganese was also studied. These were propionic, butyric, malonic, succinic, tartaric and fumaric acids. Fumaric acid, alone, yielded results which were in the least satisfactory. The deposits were never entirely adherent.

\section{(I) SEPARATION OF MANGANESE AND IRON.}

It seemed very probable that iron might be easily separated from manganese in a formic acid solution. This hope, however, seemed doomed to disappointment, for when a separation was tried under the conditions which had proved most successful for manganese alone, not much of a result was obtained, even upon continuing the electrolysis for twelve hours. The electrolyte consisted of $\mathrm{IO} \mathrm{cc}$. of a ferric ammonium sulphate solution, containing 0.1000 gram of metallic iron, Io cc. manganese sulphate, containing 0.I034 gram manganese and $5 \mathrm{cc}$. formic acid. The basket electrode served as cathode and the dish as anode. A long series of experiments was made, but the results were far from quantitative. It was also tried to see whether a uniform current density at the electrodes would prove beneficial, and therefore a number of experiments were made by introducing the solution into a beaker glass and suspending in it two platinum gauze electrodes, arranged exactly opposite each other. This was unsuccessful. It was noticed in all of this work that, in order to obtain the iron free from manganese, it was absolutely essential to have the current density at the cathode entirely uniform, that is to say, all parts of the cathode had to be equidistant from the anode surface.

1 "Quantitative Analysis by Electrolysis," p. 149. 
If there was one point of the cathode nearer to the anode, there was danger of some manganese peroxide being deposited there. Perhaps this fact explains why it has not been possible to obtain concordant results with methods proposed by different investigators up to the present time.

Electrodes of sheet platinum were also tried. The results were disappointing. It was next decided to ascertain whether the separation of the two metals could be made by retarding or preventing the deposition of inanganese dioxide altogether. Hence the electrolysis was conducted thus: The electrolyte contained ro cc. of manganese sulphate $(=0.1034$ gram of manganese) and io cc. of a ferric ammonium sulphate solution containing $0.1003 \mathrm{gran}$ of iron. To this were added Io cc. of an ammonium formate solution, and Io cc. of an ammonium sulphate solution containing 3 grams of this salt. I cc. of a solution of 45 per cent. formaldehyde was also added. The platinum dish was used as cathode, and the basket electrode, which had been used before, was introduced as anode. The solution was then made up to $\mathrm{r} 30 \mathrm{cc}$., and the electrolysis conducted in the cold, with a voltage between the electrodes of 3.5 and an amperage of 1.4 , the N.D ${ }_{100}$ at the anode being consequently 2.33 and at the cathode 1.4 . The iron was deposited in from three to five hours in a very satisfactory form, and not a trace of it could be detected in the solution. It proved to be entirely free from manganese. A little manganese peroxide precipitated on the anode in a very adherent form, but only from 0.0055 to 0.006 gram of peroxide had deposited at the end of the electrolysis when the iron was fully precipitated. No peroxide was suspended in the electrolyte. The solution was colored red from the permanganic acid formed. The deposit of iron contained varying and sometimes considerable amounts of carbon, which proved, however, no obstacle to a successful determination of this metal, as it was easily possible to dissolve the deposit off the dish very quickly by introducing distilled water and a few cubic centimeters of concentrated sulphuric acid. The solution was then transferred to a beaker and boiled for a few minutes in order to get rid of the hydrocarbons. A little granulated zinc was added in order to reduce any iron which might have become oxidized, and the solution was then titrated with a very dilute standardized solution of potassium permanganate. The whole manipulation in this way consumed, perhaps, less time than the 
ELECTROLYTIC DETERMINATION OF MANGANESE. IO5I

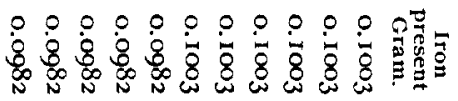

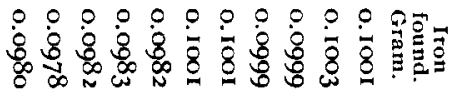

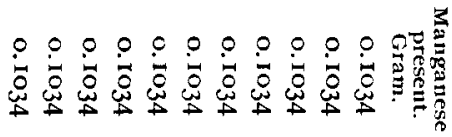

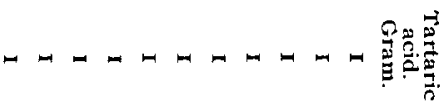

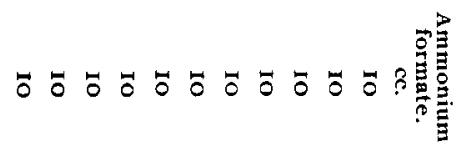

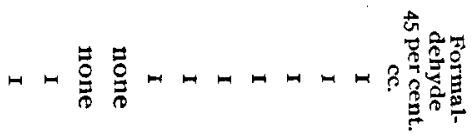

$\omega \omega \omega \omega \omega \omega \omega \omega \omega \omega \omega$

$\rightarrow A+A+A+A)$

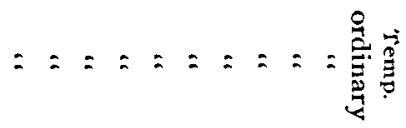

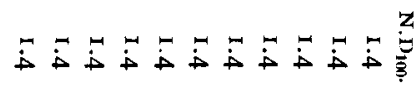

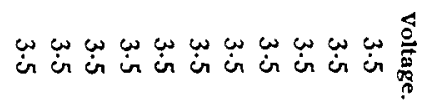


drying and weighing of the dish would have done. The following results were obtained in this manner:

The solution, when removed, had a fishy smell, due to decomposition products of the formaldehyde. The addition of the latter was discontinued after it had been shown by experiment that its presence had no influence on the result. The fishy smell of the solution did not appear after its removal. Results with and without formaldehyde are given in the above table.

1 hough it was shown by these experiments that, in an electrolyte composed as abcve, a successful separation of the iron and manganese conlcl be accomplished in much less time than by the methor of Kaeppel, yet it was felt that only half of the problem had been solved in this way. The fact that the manganese could not be determined electrolytically after the iron was all out, and that it had to be held up and thus be prevented from deposition, were sufficient stimulants to renew the effort of finding a method by which the two metals could be determined simultaneously.

The experiments with formic acid were, therefore, resumed. The electrolysis was carried out in the roughened platinum dish with the basket platinum electrode, it having been found by repeated trials that a spiral cathode could not be used, as there was invariably a precipitate of manganese oxide on it, especially on the onter rim, which was nearest to the anode, due evidently to a high current density at the cathode. The electrolyte was made up in such a manner that Io cc. of a solution, containing O. I gram of sodium sulphite, were introduced into the dish and the ferric arnmonium sulphate, containing 0.0997 gram of iron, was added. The solution immediately acquired a very dark red color. The $10 \mathrm{cc}$. of manganese sulphate were then introduced, and after that the formic acid solution. Five cc. of the latter acid of I.06 sp. gr. were found to answer well. It was discovered that the addition (twice) of I cc. of a sodium sulphite solution, containing o.I gram in I cc. for every half hour at the beginning, and an addition of an equal amount every hour until the iron was out. was very beneficial. A very good indication of the gradual deposition of the iron is furnished by the fact that on each addition of sodium sulphite the color of the solution deepens quite perceptibly, the color getting paler, the less iron there is present. It should then be watched and tested for iron from time to time, 
until no further reaction is obtained. Care must be taken in this connection that the electrode with the iron deposit on it be taken out as soon as the reaction of iron ceases. If that is not done, there is danger of some of the iron going into solution again. The basket electrode is then removed, washed off, and an auxiliary spiral electrode inserted as quickly as possible into the solution in order to prevent the manganese peroxide from dissolving in the electrolyte. Care must be taken during the time that this spiral electrode is in the solution, to insert resistance into the circuit, so as to cut down the current to o.I ampere or less, in order to prevent any precipitation on the spiral electrode. If this precaution be not taken, there will invariably be a brown-looking deposit on the electrode. The basket electrode with the deposit of iron on it is introduced into a small beaker and covered with distilled water. A few cubic centimeters of concentrated sulphuric acid are then added, when the solution of the iron will take place rapidly. The basket is then washed off and reintroduced into the electrolyte, after the spiral electrode has been taken out. Five cc. of formic acid of $1.06 \mathrm{sp}$. gr. are added, and the current raised to its original value again for the purpose of precipitating the rest of the manganese. The results obtained are shown in the following table and are very satisfactory and concordant.

\begin{tabular}{|c|c|c|c|c|c|c|c|c|c|}
\hline $\begin{array}{l}F e \\
\text { present. } \\
\text { Gram. }\end{array}$ & $\begin{array}{l}\mathrm{Fe} \\
\text { found. } \\
\text { Gram. }\end{array}$ & $\begin{array}{c}\mathrm{Mn} \\
\text { present. } \\
\text { Gram. }\end{array}$ & $\begin{array}{l}\text { Formic } \\
\text { acid I.06. } \\
\text { cc. }\end{array}$ & \multirow{2}{*}{\multicolumn{2}{|c|}{$\begin{array}{c}\text { Sodium } \\
\text { sulphite. } \\
6 \text { additions } \\
\text { o.1 g. each }\end{array}$}} & Time. & 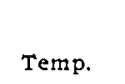 & $\begin{array}{c}\text { N. D } 100 \\
\text { cathode. }\end{array}$ & $\begin{array}{l}\text { Volt- } \\
\text { age. }\end{array}$ \\
\hline 0.1010 & 0.1008 & 0.0988 & 5 & & & $4^{1 / 2}$ & ordinary & I. 2 & 4.4 \\
\hline 0.1010 & 0.1008 & 0.0988 & 5 & $0 . \mathrm{T}$ & “" & 5 & " & I. 2 & 4.4 \\
\hline o. IOIO & o. Iolo & 0.0988 & 5 & 0.1 & " & 5 & " & 1.2 & 4.4 \\
\hline o. IOIO & 0.1008 & 0.0988 & 5 & 0.1 & $" ،$ & 5 & “" & 1.2 & 4.4 \\
\hline o. 1010 & o.ror & 0.0494 & 5 & $0 . I$ & $"$ " & $4^{1 / 2}$ & " & I. 2 & 4.4 \\
\hline o.roro & 0.1007 & 0.0494 & 5 & O.I & $"$ & $4^{1 / 2}$ & "“ & I. 2 & 4.4 \\
\hline 0.1010 & 0.1010 & 0.0494 & 5 & 0.1 & $" \prime$ & 5 & “ & I. 2 & 4.4 \\
\hline 0.1010 & 0.1009 & 0.0988 & 5 & O. I & $"$ & 5 & “ & 1.2 & 4.4 \\
\hline 0.1010 & O. IOII & 0.0988 & 5 & 0.1 & " & 5 & " & 1.2 & 4.4 \\
\hline o.roro & 0.1007 & 0.0988 & 5 & $0 . I$ & $"$ & 5 & " & 1.2 & 4.4 \\
\hline 0.1010 & 0.1011 & 0.0988 & 5 & 0.1 & $"$ & 5 & $"$ & 1.2 & 4.4 \\
\hline
\end{tabular}

It was thus established that the separation of iron and manganese could also be effected in an electrolyte, consisting mainly of formic acid. It was noticed, however, that while the sodium sulphite was very effective, so far as the iron was concerned, it retarded the deposition of the manganese. The compiete pre- 
cipitation of 0.0988 gram of manganese required from thirteen to fourteen hours, a period almost too long to make the method of practical value. Therefore, further experiments were undertaken to reduce the time actually required for the precipitation of the manganese after the previous removal of the iron. Various means were adopted to accomplish this.

An experiment was conducted in the usual manner with addition of sodium sulphite, until the iron was out and removed. Ten cc. of an ammonium acetate solution were then added and the electrolysis continued. The result was quite surprising, for after two hours the level of the solution was raised, and it was observed that there was no further precipitation of manganese peroxide. When the solution was tested, no manganese was found to be present. The time of deposition of the peroxide had thus been reduced from thirteen or fourtcen hours to seven hours. The deposit weighed 0.0992 gram while 0.0988 gram was present.

It was recognized that the presence of sodium sulphite in the electrolyte was not desirable and that it would be better, in order to remove all possible sources of error, if the separation could be effected without its use. Accordingly, ammonium acetate was introduced from the start and the quantity of sodium sulphite was cut down to 0.3 gram and then to 0.2 gram. For precaution's sake the basket electrode, with the major part of the iron on it, was also removed, but it was found that 93 per cent. of the iron had been deposited in two hours, and the rest was found when the electrode was removed at the end of the electrolysis. The surprising result was that the iron and manganese were all out of the solution at the end of four hours. These facts led to arranging the final experiments as follows: Ten cc. of manganese sulphate solution, io $\mathrm{cc}$. of a ferric ammonium sulphate solution, 5 cc. of formic acid (sp. gr. I.06) and Io cc. of an ammonium acetate solution, after dilution were electrolyzed with a current of I.I amperes, with a pressure of 3.9 volts between the electrodes, for five hours. At the end of this time the level of the solution was raised, when no further precipitation took place. The solution was then siphoned off as before, both of the electrodes washed carefully and the iron titrated in the usual manner, while the manganese peroxide was ignited and weighed. The following table shows the close agreement of the results obtained: 


\begin{tabular}{|c|c|c|c|c|c|c|c|c|c|c|}
\hline 晜 & 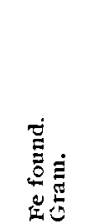 & 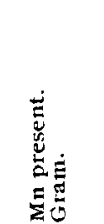 & 总 & 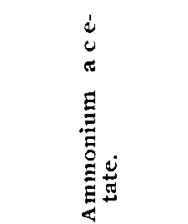 & 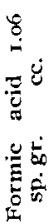 & 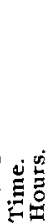 & 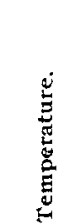 & 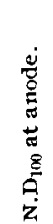 & 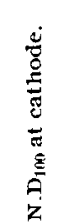 & 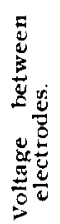 \\
\hline 0996 & 0.0996 & 0.0988 & 0.0990 & $\begin{array}{c}\text { Io cc. }+ \text { Io } \\
\text { drops } \mathrm{Na}_{2} \mathrm{SO}_{3}\end{array}$ & 5 & 4 & $\begin{array}{l}\text { ordi. } \\
\text { nary. }\end{array}$ & I. I & I. 83 & 9 \\
\hline 0.0996 & 0.0994 & 0.0988 & $0.099 \mathrm{r}$ & $"$ & 5 & 4 & “ & I. I & I. $8_{3}$ & 9 \\
\hline 0.0996 & 0.0994 & 0.0988 & 0.0986 & $\begin{array}{l}\text { Iocc., no } \\
\mathrm{Na}_{2} \mathrm{SO}_{3} .\end{array}$ & 5 & 5 & " & I. I & 1.83 & \\
\hline 0.0996 & 0.0995 & 0.0988 & 0.0988 & $"$ & 5 & 5 & " & I. I & 1.83 & .9 \\
\hline 0.0996 & 0.0995 & 0.0988 & 0.0990 & " & 5 & 5 & “" & I. 1 & I. 83 & 9 \\
\hline 0.0996 & 0.0994 & 0.0988 & 0.0990 & “" & 5 & 5 & “ & I. I & $1.8_{3}$ & 9 \\
\hline
\end{tabular}

The deposit of iron had a shining, metallic appearance while the manganese peroxide was black, lustrous, and adherent to the dish.

\section{(2) SEPARATION OF MANGANESE AND ZINC.}

A solution of zinc sulphate, containing o.I gram of metal in Io cc., was used. The electrolysis was carried out in a roughened platinum dish serving as anode, while the platinum basket electrode was connected as cathode. It was found that the deposit of zinc showed an extreme tendency to come down in spots upon the cathode, and the basket electrode had to be carefully adjusted so that it was equidistant from the sides of the dish. In this case the addition of ammonium formate exerted beneficial influence on the character of the zinc deposit, the best results being obtained with a solution containing 0.1034 gram of manganese, 0.1000 gram of zinc, Io cc. of formic acid (sp. gr. 1.06), and 5 cc. of a solution of ammonium formate obtained by neutralizing formic acid (sp. gr. I.06) with ammonia.

\begin{tabular}{|c|c|c|c|c|c|c|c|c|}
\hline$\underset{\text { present. }}{\text { Gram. }}$. & $\begin{array}{l}\text { Mn } \\
\text { found. } \\
\text { Gram. }\end{array}$ & $\begin{array}{c}\underset{2 n}{ } \\
\text { present. } \\
\text { Gram. }\end{array}$ & $\begin{array}{l}\mathrm{Zn} \\
\text { found. } \\
\text { Gram. }\end{array}$ & $\begin{array}{l}\text { Time. } \\
\text { Hours. }\end{array}$ & $\begin{array}{l}\text { Tempera- } \\
\text { ture. }\end{array}$ & $\begin{array}{l}\text { N.D } D_{100} \\
\text { anode. }\end{array}$ & $\begin{array}{l}\text { N. } \mathrm{D}_{1 m} \\
\text { cathode. }\end{array}$ & $\begin{array}{l}\text { Volt- } \\
\text { age. }\end{array}$ \\
\hline 0.1034 & 0.1037 & 0.1000 & 0.0998 & I I & ordinary & 1.0 & 1.66 & 5.4 \\
\hline 0.1034 & 0.1033 & 0.1000 & 0.1001 & I I $1 / 2$ & $"$ & 1.0 & I. 66 & $5 \cdot 4$ \\
\hline .1034 & 0.1036 & 0.1000 & 0,1003 & I I & " & 1.0 & 1.66 & 5.4 \\
\hline
\end{tabular}

The writer feels justified in claiming that the present investigation has conclusively proved that not only can manganese be easily and accurately determined in the electrolytic way in a formate solution, but that it can also be completely separated in a very simple manner from iron. Indeed, when compared with 
any other gravimetric procedure which has been employed for the separation of these metals the electrolytic method is superior in every particular. It is readily executed, it requires less time, and the results afforded by it are most satisfactory. Finally, the separation of manganese from zinc, as described above, is of practical value.

LAIVERSITY OF PENNSYIVANIA.

\section{ON A COLORIMETRIC METHOD FOR THE ESTIMATION OF PHOSPHATES IN THE PRESENCE OF SILICA.'}

BY OSWALD SCHREINER.

Received fuly 29, 2903

THE estimation of small amounts of phosphates in waters and aqueous extracts of soils and plants is a matter of daily occurrence in the study of field conditions of the soils, of surface and subsurface waters and growing crops, as carried on in the Bureau of Soils, L. S. Dept. of Agriculture. The method first used by Lepierre, ${ }^{2}$ also by Jolles and Neurath, ${ }^{3}$ and perfected by Woodman and Cayvan," Veitch," and others, consisted in measuring the color developed by phosphates with ammonium molybdate in nitric acid solution against a known solution of phosphate as standard. As silica gives the same coloration with this reagent, its almost unfailing presence in natural waters is a disturbing factor. In the Woodman and Cayvan method, the silica is removed by evaporating once or twice to dryness with nitric acid and heating for two hours in an oven at $100^{\circ}$. The phosphate is then dissolved and separated from the insoluble silica by filtration, and estimated colorimetrically. The need of a more rapid field method incluced Prof. F. H. King, Chief of the Division of Soil Management, to direct the investigation of silica and phosphate solutions, which has led to the method here reported.

In the method given in the following pages, the silica is estimated simultaneously with the phosphates. The method is based on the experimental observation that silica solutions will give different intensities of coloration under different conditions, while phosphates give the same coloration under these different con-

1 Published by permission of the Secretary of Agriculture.

2 Bull. Soc. Chim., 15, 1213.

${ }^{3}$ Monatsh. Chem., 19, 5.

4 This Journal, 23, 96 .

5 Ibid., $25,169$. 